\title{
Feeding Relations of the Atlantic Silverside Menidia menidia in the Minas Basin, Bay of Fundy
}

\author{
M. C. Gilmurray and G. R. Daborn \\ Department of Biology, Acadia University, Wolfville, Nova Scotia, BOP 1XO, Canada
}

\begin{abstract}
Feeding habits of the Atlantic silverside Menidia menidia were studied from June to November 1979. Analysis of gut fullness with respect to tidal state suggests that feeding occurs on ebb tide and not during flooding tide. It is suggested that extreme turbidity prevents feeding on the rising tide. The major prey of larvae and early juveniles was Eurytemora herdmani; larger silversides $(>100 \mathrm{~mm})$ fed more heavily upon Corophium volutator, Diastylis polita, Crangon septemspinosa, various isopods and insects. These benthic organisms may be mude more accessible to the silverside by tidal turbulence causing resuspension of the sediments and benthos during the flooding tide. Tiderelated movements of $M$. menidia result in maxumum utilization of these periodıcally available food resources.
\end{abstract}

\section{INTRODUCTION}

The Bay of Fundy is a macrotidal estuary with tidal amplitudes increasing from $5 \mathrm{~m}$ at the mouth to $>16 \mathrm{~m}$ in Minas Basin at the head of the system. The high energy of the system results in considerable vertical turbulence that maintains much of the sediments derived from erosion of friable deposits along the coastline in suspension. Suspended sediment loads range from $<5 \mathrm{mg} \mathrm{l}^{-1}$ in the outer Bay to $>1 \mathrm{~g} \mathrm{l}^{-1}$ in inner reaches of the estuary; recent research has demonstrated that these latter regions support large zooplankton and benthos populations (Daborn and Pennachetti, 1979b; Gratto, 1979; McCurdy, 1979; Yeo, 1978). It seems probable that secondary production in the area is supported primarily by benthic diatoms and saltmarsh production made available by tidal flushing of extensive marshlands and mudflats. Benthic organisms are of great importance in the support of migratory shorebirds during their fall migration (Boates, 1978, 1979) and also for older juvenile and adult fish (Gilmurray, 1980), while the zooplankton is probably the most important component of larval and juvenile fish diet (Imrie and Daborn, 1981).

In view of the extreme turbidity of the water and consequent paucity of phytoplankton, and the low level of adult fisheries, it has been suggested that production in the Bay of Fundy is relatively low (Huntsman, 1952; Jermolajev, 1958). Nonetheless, a major question posed by potential tidal power developments is whether these inner regions play a nursery role in the support of distant fish populations.

The objectives of this study were therefore to assess the relative importance of plankton, benthos and saltmarsh entomofauna in the diet of the Atlantic silverside, Menidia menidia, and to investigate the influences of diel and tidal periodicities and ontogenic changes on diet composition.

\section{METHODS}

Weekly seine collections were made over $24 \mathrm{~h}$ periods from June 13 to August 6, 1979 at Kingsport, Nova Scotia, Canada $\left(40.09^{\circ} \mathrm{N}, 62.22^{\circ}\right.$ W, Fig. 1). Sampling was reduced to $12 \mathrm{~h}$ periods on August 23 and September 12, and restricted to $1 \mathrm{~h} \mathrm{fortnight}^{-1}$ until November 20,1979 . A $9.1 \times 2 \mathrm{~m}$ seine ( $5 \mathrm{~mm}$ mesh) was hauled 5 times each hour parallel to shore for a distance of approximately $20 \mathrm{~m}$ before being pursed on the beach. Samples were preserved immediately in buffered $10 \%$ formalin in seawater.

All fish were counted in samples. Gut contents of $<15$ fish sample ${ }^{-1}$ were examined. Total length of each fish was recorded $( \pm 0.05 \mathrm{~mm})$, the digestive tract was removed, cut open and contents flushed into a Petri dish. Food types were identified, enumerated and their lengths recorded. Estimation of total ingested 


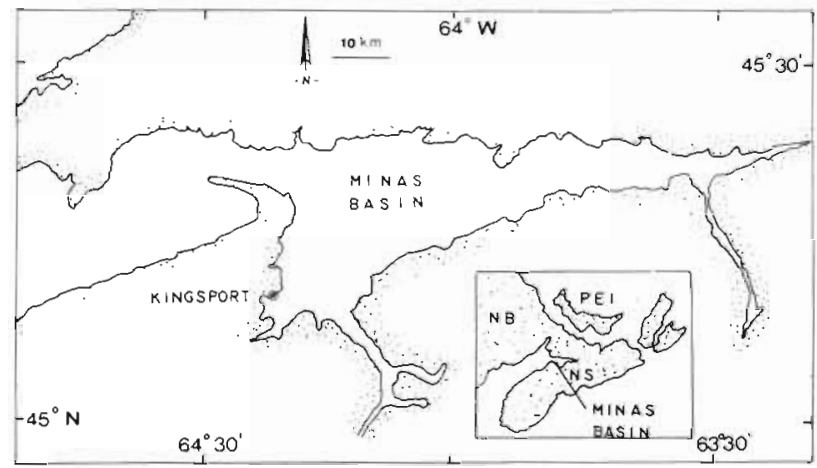

Fig. 1. Minas Basin and sampling site (Kingsport). Inset: Maritime Provinces of Canada; NB New Brunswick, PEI Prince Edward Island, NS Nova Scotia

biomass was determined from empirical length-weight relationships that previously had been calculated for various organisms in Minas Basin.

Percent composition by weight of each diet item was estimated for each of 5 size classes of Menidia menidia. Hureau's index of fullness Ir was employed in calculating fullness, where:

$I r=$ ingested biomass/body weight $\times 100 \%$ (Berg, 1979).

Correlation coefficients for fullness vs tidal state and fullness vs time of day were calculated and the MannWhitney U-test used to examine diel distributions of Menidia menidia.

\section{RESULTS}

The diet of Menidia menidia is varied. Major ingredients by weight and number included the copepod, Eurytemora herdmani, the amphipod Corophium volutator, and the cumacean Diastylis polita; lesser components included Jaera marina, Crangon septem-

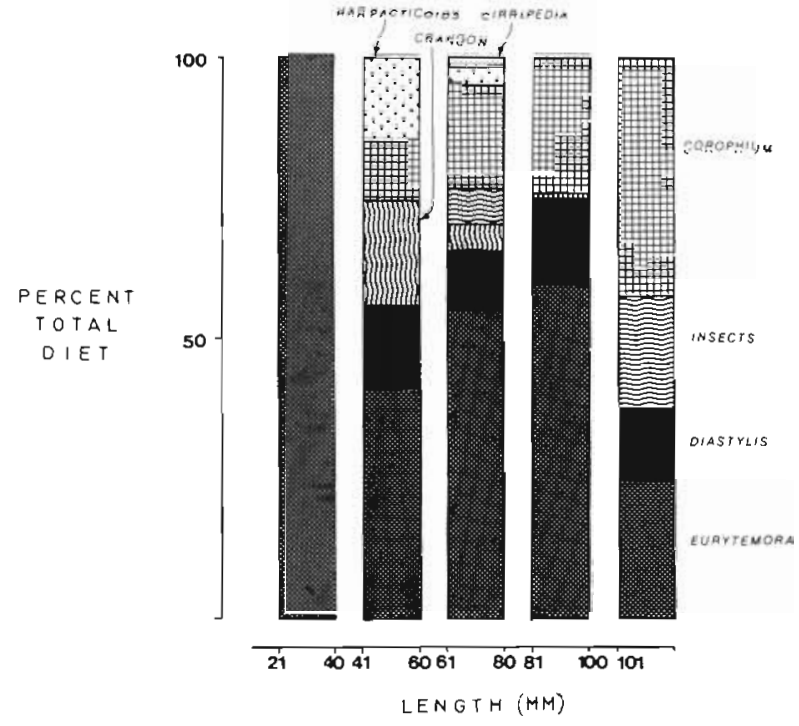

Fig. 3. Menidia menidia. Relationships between diet composition (\% total ingested biomass) and body length

spinosa and a variety of insects and harpacticoid copepods.

Seasonal variations in the diet were evident, presumably as a function of local food abundance and developmental stage of the consumer (Fig. 2). Until July 10 and after August 6, Eurytemora herdmani constituted an important component of the diet. Corophium volutator usually contributed $>20 \%$ by weight of total gut contents until the end of September, although the proportion increased to $>50 \%$ on June 20, July 24 and August 2. Insects (i.e. chironomid larvae and Formicidae) and Crangon septemspinosa larvae were important during July and August; occasionally they represented as much as $65 \%$ of the total gut weight. Diastylis was found in relatively large

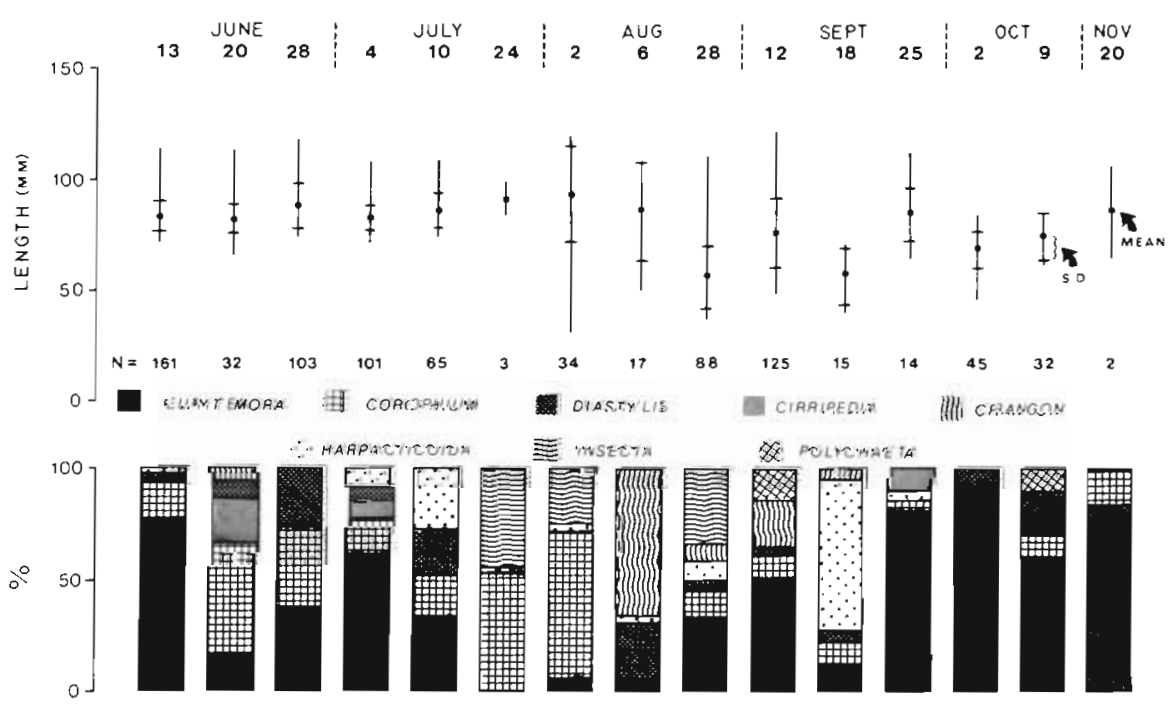

Fig. 2. Menidia menidia. Diet composition. 13 June-20 Nov. 1979. Upper: Mean, standard deviation and range of body length on each sample date. Lower: Diet composition expressed as $\%$ of total ingested biomass. N: No. in sample 
proportions (e.g. June 28, July 4 and 10, August 6, October 2-November 20). Harpacticoid copepods were usually evident in small quantities throughout the season.

Analysis of the data (Fig, 2) in terms of diet composition suggests, therefore, that adults fed initially upon the copepod Eurytemora herdmani and on smaller numbers of Corophium volutator. After July 4 the diet became more varied, possibly because of the midsummer decline in abundance of Eurytemora herdmani (Daborn and Pennachetti, 1979b) and appearances of young Corophium, crangonids and larval insects. During August silverside captures were mainly of juveniles which are unable to eat food of any great size. As a result, larger $C$. volutator and Crangon septemspinosa were not utilised. Towards the end of the summer when meroplankton components of the plankton and benthic populations usually decline (Daborn and Pennachetti, 1979b), E. herdmani once again became the major species both in the plankton (Gilmurray, 1980) and in the diet of developing juvenile silversides.

The relationships between diet and ontogeny of the silverside are shown in Fig. 3 . The $20-40 \mathrm{~mm}$ size class
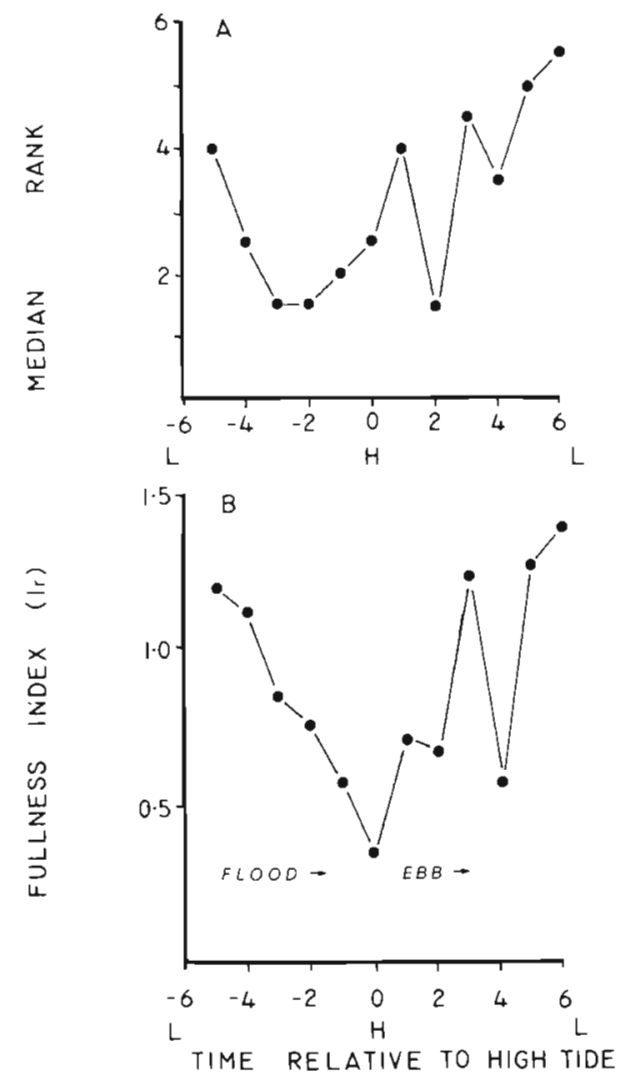

Fig. 4. Menidia menidia. Relationships between median rank abundance (A) and gut fullness index (B) and stage of tide. $\mathrm{H}$ : High tide; L: low tide fed exclusively upon Eurytemora herdmani even though plankton tows indicated that Acartia tonsa was the dominant member of the midsummer holoplankton (Gilmurray, 1980). The 41-60 and 61-80 mm size classes fed primarily upon E. herdmani but also upon Diastylis polita, insects, Crangon septemspinosa, Corophium volutator and harpacticoids. The largest silversides (>81 mm) took greater proportions of $C$. volutator, and maintained a similar intake of $D$. polita as intermediate size classes.

In view of the major tidal excursions of the area we examined relationships between the degree of gut fullness and both time of day and tidal state. There were no correlations between either fullness and time of day $(r=-0.04, \mathrm{p}>0.05)$ or fullness and tidal state ( $r$ $=0.01, \mathrm{p}>0.05)$. Similarly, catch sizes during night and day periods were not significantly different. As shown in Fig. 4A, the numbers of Menidia menidia, captured were highest near the times of low and high tide, but showed a steady decline during the first few hours of the flooding tide. Since these results were combined from ten 24 -h or 12 -h sample series including both day and night high tides, this pattern is not determined by diel activity cycles. On the contrary, the data suggest that silversides do not follow the advancing wave front as we had previously hypothesised. The decline in numbers presumably reflects their general distribution over the intertidal zone following a concentration in subtidal areas at low water. Numbers captured increased notably, however, during the last $2 \mathrm{~h}$ of the flood tide, and generally continued to increase over the ebb as falling water levels concentrated the fish.

Gut fullness declined steadily over the flood tide, reaching a minimum at high tide, but rapidly rose after high tide (Fig. 4B). This seems to indicate that Menidia menidia feed primarily on the ebb and at low tide, and little or not at all on the rising tide.

\section{DISCUSSION}

The results suggest that the local tidal regime exerts a major influence in the feeding activity of Atlantic silverside. Although the fish advance over the mudflat on the flooding tide, they apparently do not feed during this period, but do so extensively on the ebbtide. An earlier study, as this one, reveal that benthic organisms such as Corophium volutator, Diastylis polita, isopods and various sedentary polychaetes form important components of the diet of Menidia menidia (Imrie and Daborn, 1981). This fish, however, has a strongly hypergnathous mouth that is clearly more suited to feeding on plankton or pleuston than on benthos. While C. volutator, cumaceans and isopods are all 
capable of active swimming, we hypothesised that their prevalence in the diet was directly related to tidal resuspension of these organisms. Accordingly, we anticipated that the fish would advance promptly behind the water's edge on the rising tide, and feed actively during that time. Such is clearly not the case. It may be, however, that the rapid rise in gut fullness immediately after high tide results from active feeding on benthic organisms brought into the water column by vertical turbulence during the flood.

There are considerable differences in the degree of vertical turbulence in the water during ebb and flood periods. On the flood the water is vertically homogeneous with respect to temperature, salinity and suspended sediments as a consequence of the high tidal energy (Daborn and Pennachetti, 1979a). Much of this energy is dissipated in triction as the water advances over the mudflat, and at high tide gravity settling of larger suspended particles occurs. Thus, except on very windy days, turbidity of ebbing waters is considerably less than that of the rising tide and hence light penetration is greater. We now postulate, therefore, that Menidia menidia which is primarily a visual particulate feeder, feeds mostly during the ebb and low tide periods because of the greater visibility afforded then.

Temporal changes in diet composition over the months studied result from a combination of changes in food availability and ontogeny of the predator. In early June, the most abundant zooplankter in this part of Minas Basin is Eurytemora herdmani (Daborn and Pennachetti, 1979b; Gilmurray, 1980), but in the summer this species is primarily to be found in cooler, deeper waters and the plankton in shallow waters is dominated by Acartia tonsa. Nonetheless, during July and August juvenile silversides were still feeding quite extensively on $E$. herdmani although contemporaneous plankton samples yielded few specimens. It is noteworthy that $A$. tonsa was not eaten, even though it was the most abundant species in the plankton. We do not know whether this is a function of prey selection by Menidia menidia or of predator avoidance by $A$. tonsa.

The gradual increase in consumption of Corophium volutator in summer is coincident with population trends of the prey: abundance increased dramatically following the first breeding phase in June. During August, a decline in consumption of $C$. volutator was coincident with arrival of large numbers of migratory shorebirds whose major food resource is this tubicolous amphipod (Boates, 1978, 1979).

In this study, insects and other terrestrial and saltmarsh arthropods represented a small component of the diet. This is in contrast with results obtained in 1978 when $<40 \%$ of captured silversides had been feeding on non-aquatic arthropods (Imrie and Daborn, 1981). Contemporaneous studies of the saltmarsh entomofauna suggest that insect populations were much lower in the cool wet summer of 1979 than the year before (O. Krepinsky, pers, comm.).

The Atlantic silverside is apparently a very opportunistic predator, utilising a wide range of prey. Tidal movements exert considerable influence on temporal utilisation and, perhaps, on food availability, although this influence may be less than that of the wind, which can both increase turbidity, thereby impeding visibility of aquatic prey, and increase the allochthonous input of non-aquatic food from saltmarshes or land. Perhaps the point of most significance, however, is the trophic overlap between the silverside (and other local fish) and the large number of shorebirds that visit the area during their fall migration. Both groups feed extensively on Corophium volutator which thus appears to play a major role in the trophic dynamics of the southern bight of Minas Basin.

Acknowledgements. This research was supported in part by Canadian National Sportsmen's Fund Grant 2-R41 and by National Sciences and Engineering Research Council of Canada Grant A9679 awarded to G. R. Daborn, and by Acadia University fellowships. Field work was facilitated by cooperation with Kim Strong, Anna Redden, the Zooplankton-sediment Summer Job Corps, 1979. We also appreciate assistance and information provided by John O Neill, Sherman Boates, Frank Calder, Ondrej Krepinsky, Dr D. Tosh, Peter Schwinghamer, and Isi Salinas.

\section{LITERATURE CITED}

Berg, J. (1979). Discussions of methods of investigating the food of fishes, with reference to a preliminary study of the prey of Gobiusculus flavescens (Gobiidae). Mar Biol. 50: 263-273

Boates, J. S. (1978). Invertebrates and sediment characteristics of the Starrs Point lower intertidal region. Unpublished Final Report of Summer Job Corps Projekt 16-01003 for the National Research Council of Canada, Halifax, N.S.

Bodtes, J. S. (1979). Shorebird-invertebrate studies in the Starrs Point area, Minas Basin. Unpublished final report of Summer Job Corps Project 16-01-0075 for the National Research Council of Canda, Halifax, N.S.

Daborn, G. R., Pennachetti, C. (1979a). Physical oceanographic and sedimentological studies in the southern bight of Minas Basin. Proc. N.S. Inst. Sci. 29: 29: 315-333

Daborn, G. R., Pennachetti, C. (1979b). Zooplankton studies in the southern bight of Minas Basin. Proc N.S Inst. Sci 29: $465-481$

Gilmurray, C. (1980). Occurrence and feeding habits of some juvenile fish in the southern bight of Minas Basin. Nova Scotia, 1979. Unpublished M.Sc. thesis, Acadia University, Wolfville, N.S.

Gratto, G. W. (1979). The biology of the amphipod Corophium volutator (Pallas) in the western Minas Basin. Unpublished M.Sc. thesis, Acadia Univ., Wolfville, N.S. 
Huntsman, A. G. (1952). The production of life in the Bay of Fundy. Proc. R. Soc. Can. 46: 15-38

Imrie, D. M. G., Daborn, G. R. (1981). Food habits of some immature fish of Minas Basin, Bay of Fundy. Proc. N.S. Inst. Sci. (in press)

Jermolajev, E. G. (1958). Zooplankton of the inner Bay of Fundy. J. Fish. Res. Bd Can. 15: 1219-1228
McCurdy, P. (1979). Intertidal invertebrates of Scots Bay and western Minas Basin, Nova Scotia. M.S.c. thesis, Acadia [niversity, Wolfville, N.S.

Yeo, R. K. (1978). Animal sediment relationships in the Minas Basin, Bay of Fundy. M.Sc. thesis, McMaster University, Hamilton, Ontario

This paper was presented by Professor R. L. Haedrich; it was accepted for printing on June 5, 1981 